\title{
Pharmaceutical Care in Children Self-reported knowledge, attitudes and competency of final-year pharmacy students in Jordan
}

*Tareq L. Mukattash, ${ }^{1}$ Anan S. Jarab, ${ }^{1}$ Rana K. Abu-Farha, ${ }^{2}$ Eman Alefishat, ${ }^{3}$ James C. McElnay ${ }^{4}$

$$
\begin{aligned}
& \text { الرعاية الصيدلانية للأطفال } \\
& \text { المعرفة و التوجهات والقدرات لدى طلاب السنة الأخيرة في كليات الصيدلة في الأردن }
\end{aligned}
$$

$$
\text { طارق لويس مقطُش، عنان صادق جرّاب، رنـا كمال أبو فرحة، إيمان العفيشات، جيمس ماكيلناي }
$$

ABSTR ACT: Objectives: Pharmacists require a baseline level of knowledge in paediatric pharmaceutical care in order to be able to adequately care for paediatric patients and counsel their families. This study aimed to explore the self-reported knowledge, attitudes and competency of final-year pharmacy students in Jordan regarding paediatric pharmaceutical care. Methods: This study took place in Jordan between November 2016 and May 2017. A 28-item questionnaire was designed and administered to 400 students from all pharmacy programmes in Jordan during their final year of training. Results: A total of 354 students agreed to take part in the study (response rate: $88.5 \%$ ). Most respondents (95.2\%) were aware of the term 'paediatrics'. However, almost one-third of the respondents (30.5\%) reported never having taken paediatric dose calculation courses and more than half $(55.6 \%)$ were unfamiliar with the term 'off-label medicines'. Moreover, most respondents $(65.1 \%)$ had low knowledge scores ( $\leq 2$ out of 5 ) when presented with realistic paediatric case scenarios. There were no significant differences in knowledge and attitudes between undergraduate and doctoral students or between those from public or private universities $(P>0.05)$. Conclusion: The findings of this study highlight an alarming deficiency in paediatric pharmaceutical knowledge among final-year pharmacy students in Jordan. As such, paediatric-related content should be emphasised in the pharmacy curricula of Jordanian universities so that pharmacy students receive more formalised education and more extensive training in this area.

Keywords: Pharmaceutical Care; Pediatrics; Pharmacy Students; Knowledge; Attitudes; Competency-Based Education; Jordan.

الملخص: الهذف: يحتاج الصيادلة إلى مستوى أساسي من المعرفة في الرعاية الصيدلانية للأطفال حتى يتمكنوا من تقديم الرعاية

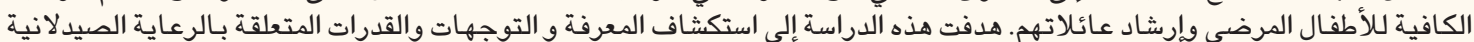

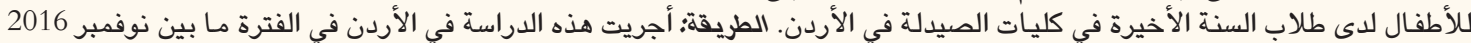

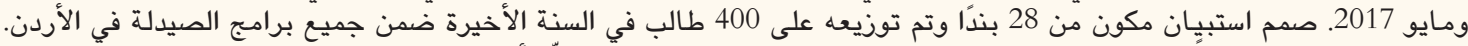

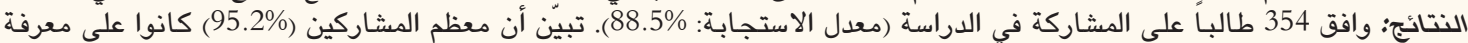

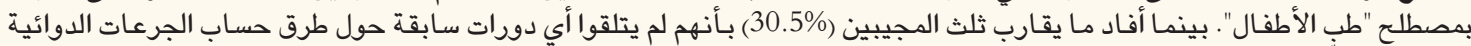

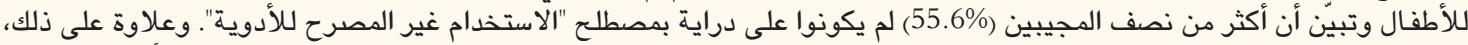

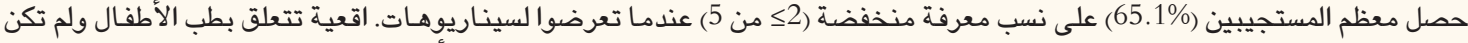

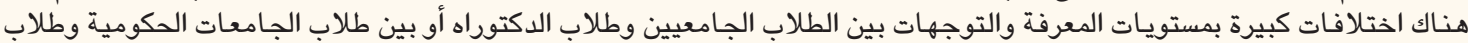

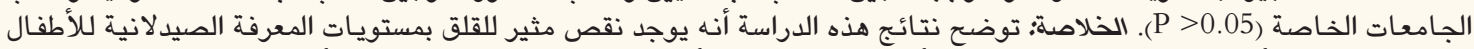

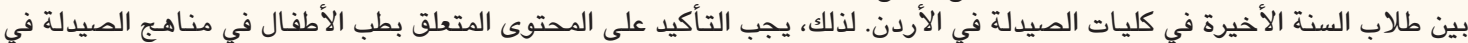

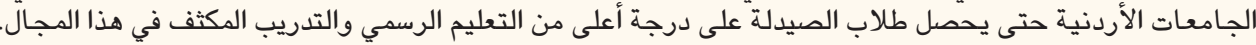

$$
\text { الكلمات المفتاحية: الرعاية الصيدلانية؛ طب الأطفال؛ طلاب الصيدلة؛ الصعرفة؛ التوجهات؛ التعليم القائم على الكفاءة؛ الأردن. }
$$

\section{Advances in KNOWLEDGE}

To the best of the authors' knowledge, this study is the first to explore the self-reported knowledge, attitudes and competency of final-year pharmacy students regarding paediatric pharmaceutical care.

The present study highlights a perceived lack of specialised paediatric education and training in the pharmacy curricula at Jordanian universities.

\section{Application to Patient Care}

The findings of the current study highlight the importance of incorporating more specialised paediatric content within the pharmacy curricula in Jordan; this will hopefully lead to the provision of safer and more effective pharmaceutical care to paediatric patients. 


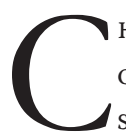

HildREN REPRESENT a SIGNIFICANT PROPortion of the population requiring pharmacy services in a variety of hospital and community settings; as such, pharmacists play an essential role in paediatric care. $^{1-4}$ Due to advances in paediatric medicine, the increasing complexity of childhood diseases and unique dosing and pharmacokinetic challenges, there is growing need to educate pharmacists in basic paediatric competencies. Furthermore, it is estimated that the use of prescription medications among paediatric patients is substantial; according to the Centers for Disease Control and Prevention, 14-20\% of patients under 19 years old surveyed in 2008 reported having used at least one prescription drug in the preceding month.,6 As a result, pharmacy curricula should emphasise a minimum level of paediatric pharmacotherapy competence; this could potentially help to lower the rate of paediatric medication errors. ${ }^{1,7}$

The provision of pharmaceutical care to children can be challenging, especially with regards to the appropriate drug, dosage and route of administration. Because of their relative lack of chronic ailments, children usually require fewer medications compared to adults; this, compounded with the various ethical and logistical barriers to studying the effects of medications among children, means that there are very few medications licensed for use among children. ${ }^{4}$ Medications without the proper marketing authorisation are referred to as 'unlicensed', while off-label medications indicate licensed medicines which are prescribed or used in a manner not consistent with recommendations, for instance in terms of dose, route of administration or recommended age.

According to the United Nations, 37.7\% of the population in Jordan is under 14 years old. ${ }^{8}$ Moreover, pharmacists in Jordan often act as primary care providers as, for financial reasons, they are often the first and only port of call for healthcare advice and medicine use by patients. Wazaify et al. also reported that pharmacists in Jordan often dispense non-prescribed medications, including antibiotics. ${ }^{9}$ As such, it is imperative that pharmacists in Jordan have the necessary knowledge to provide safe and adequate care to paediatric patients, including the information needed to dispense medications and counsel paediatric patients or their guardians. ${ }^{7,10}$ However, due to a lack of national guidelines regarding paediatric care, pharmacists often rely on knowledge received during their education and training. The present study aimed to explore the self-reported knowledge, attitudes and competency of final-year pharmacy students in Jordan regarding paediatric pharmaceutical care, including assessment, treatment and dosage. To the best of the authors' knowledge, this is the first study to directly explore pharmacy students' perceptions and attitudes regarding this topic.

\section{Methods}

This study took place in Jordan between November 2016 and May 2017 and involved all 400 final-year undergraduate (Bachelor of Science) and postgraduate (Doctor of Pharmacy) students from all pharmacy programmes in Jordan. Only students who had completed $\geq 85 \%$ of the credit-hours required for graduation at their specific university were included. A survey was designed to assess the students' knowledge, attitudes and competency regarding paediatric pharmaceutical care. The content of the survey was based on the findings of an extensive literature review, in addition to one-on-one interviews conducted with staff members at all pharmacy faculties in Jordan to assess the paediatric-related content of the existing curricula. ${ }^{11-17}$ Subsequently, the survey was examined by experts in the fields of clinical pharmacy, pharmacy practice and paediatrics to determine the fitness for purpose and face and content validity of the instrument. The final version of the questionnaire was then tested in a pilot group of 50 final-year pharmacy students who were not included in the full study. The instrument was deemed valid, with a Cronbach's alpha coefficient of 0.87 for internal consistency.

The final English-language questionnaire consisted of 28 items and was divided into four sections. The first section (items 1-7) collected the participants' demographic information to allow for the examination of variability in responses according to various characteristics. Section two (items 8-14) aimed to explore respondents' knowledge of paediatric treatment and dosing. The third section (items 15-22) explored respondents' perceptions of their abilities regarding paediatric treatment and dosing. The final section (items 23-28) consisted of five realistic case scenarios covering common paediatric complaints [Table 1]. These case scenarios were chosen based on the recommendations of colleagues specialising in paediatric therapeutics and were assessed by a panel of experts prior to their inclusion in the survey. For each case scenario, the participants had to choose the single correct response out of five multiple-choice options; each correct answer received one point while wrong answers were scored as zero. The total knowledge score for the section was calculated by summing the correct answers, with five being the highest score, indicating perfect knowledge, and zero the lowest, indicating a complete lack of knowledge.

The students were invited to take part in the survey at the end of specific lectures, as determined by appropriate members of the administration at each university. Before distributing the questionnaire, one of the researchers introduced the study to the students and briefly described the contents and purpose of 
Table 1: Five realistic case scenarios to assess paediatric pharmaceutical knowledge among final-year pharmacy students in Jordan

Case scenario
A six-month-old girl has become inc-
reasingly irritable and has been waking
up four-to-five times each night. She
also seems to be drooling excessively
and biting on hard objects constantly. A
brief examination of her mouth shows
red tender gums. No teeth are present
and she is afebrile. What would you
recommend?

A three-month-old infant has had a severe rash for the past four days. It is confined to the diaper area and is very inflamed and tender. Vesicular satellite lesions are present on the periphery of the main erythematous area. The mother uses only cloth diapers and has not changed soaps or normal methods of diaper care since her child was born. What would you recommend to treat this child?

A three-month-old female has had nasal congestion, rhinorrhoea and a cough since yesterday. She has not had a fever and is eating well but did not sleep well last evening. Her mother called her paediatrician and was told that her daughter most likely has a cold caused by a virus. How can the child's symptoms be treated?

You receive a call from a mother asking about her child's constipation. All of the following are true regarding paediatric constipation, except which of the following?

The mother of a 12-month-old baby weighing $10 \mathrm{~kg}$ has stated that her son has been warm for the last 12 hours. His rectal temperature taken 15 minutes ago was $38.7^{\circ} \mathrm{C}$. Which of the following would be an appropriate recommendation?

the survey. Students were informed that completion of the questionnaire would take approximately 10 minutes In order to avoid duplicate responses, all students who had previously completed the questionnaire were asked to leave the room. The questionnaires were collected as soon as they were completed.

Following data collection, the survey responses were coded and entered into a customised database using the Statistical Package for the Social Sciences (SPSS), Version 21.0 (IBM Corp., Armonk, New York, USA). Descriptive results were presented as means and standard deviations for continuous variables and percentages for qualitative variables. A simple linear regression analysis was performed to identify factors significantly affecting knowledge scores. All tests were two-tailed. A $P$ value of $\leq 0.05$ was considered statistically significant.

This study received ethical approval from the Institutional Review Board of King Abdullah University Hospital, Ar Ramtha, Jordan (\#20160191). All students
Table 2: Demographic characteristics of final-year pharmacy students in Jordan $(\mathrm{N}=354)$

\begin{tabular}{lc} 
Characteristic & $\mathbf{n}(\%)$ \\
Gender & \\
Male & $67(18.9)$ \\
Female & $287(81.1)$ \\
Nationality & \\
Jordanian & $279(78.8)$ \\
Other & $75(21.2)$ \\
Type of university & \\
Public & $270(76.3)^{*}$ \\
Private & $84(23.7)$ \\
Type of degree & $179(50.6)$ \\
Bachelor/undergraduate & $175(49.4)$ \\
Doctoral/postgraduate & \\
Year of study & $73(20.6)$ \\
Fourth & $224(63.3)$ \\
Fifth & $57(16.1)$ \\
Sixth & $70(19.8)$ \\
GPA & $38(10.7)$ \\
Excellent & \\
Very good & \\
Good & \\
Satisfactory & \\
\hline
\end{tabular}

GPA = grade point average. *Comprising 131 (37\%) students from the University of Jordan and 139 (39.3\%) from the Jordan University of Science E Technology.

were informed that participation in the study was voluntary in nature. All participants provided informed written consent before completing the questionnaire and were assured of the anonymity and confidentiality of their data.

\section{Results}

A total of 354 students took part in the study (response rate: $88.5 \%)$. The majority were female $(81.1 \%)$ and Jordanian (78.8\%). In addition, most students (76.3\%) were enrolled in public universities, such as the University of Jordan (37\%) and the Jordan University of Science \& Technology (39.3\%). As students in Jordan are able to register for more credit-hours in order to graduate earlier, there was a range of fourth-, fifth-and sixth-year students [Table 2].

Most respondents (95.2\%) were aware of the term 'paediatrics', with $86.7 \%$ reporting having gained this knowledge during their pharmacy education. However, 
Table 3: Knowledge and attitudes of final-year pharmacy students in Jordan regarding paediatric pharmaceutical care $(\mathrm{N}=354)$

\begin{tabular}{|c|c|}
\hline Item & Response, n (\%) \\
\hline \multicolumn{2}{|l|}{ Are you aware of the term 'paediatrics'? } \\
\hline Yes & $337(95.2)$ \\
\hline No & $17(4.8)$ \\
\hline \multicolumn{2}{|l|}{ Where did you first hear this term? } \\
\hline During my pharmacy studies & $307(86.7)$ \\
\hline During my hospital training & $12(3.4)$ \\
\hline $\begin{array}{l}\text { During my community pharmacy } \\
\text { training }\end{array}$ & $6(1.7)$ \\
\hline Other & $26(7.3)$ \\
\hline I have never heard of the term & $3(0.8)$ \\
\hline \multicolumn{2}{|c|}{$\begin{array}{l}\text { If familiar with the term 'paediatrics' through your education, } \\
\text { in which course did you learn this term? }\end{array}$} \\
\hline Many & $140(39.5)$ \\
\hline Pharmacokinetics and dose calculation & $12(3.4)$ \\
\hline Medicinal chemistry and organic chemistry & $3(0.8)$ \\
\hline Pharmacotherapy and pharmacology & $152(42.9)$ \\
\hline Pharmacy practice & $18(5.1)$ \\
\hline $\begin{array}{l}\text { Physical pharmacy, industrial pharmacy } \\
\text { and dosage formulation }\end{array}$ & $10(2.8)$ \\
\hline Other & $16(4.5)$ \\
\hline None & $3(0.8)$ \\
\hline \multicolumn{2}{|c|}{$\begin{array}{l}\text { During your education, did you take any courses on paedia- } \\
\text { tric dosing or paediatric dose calculation? }\end{array}$} \\
\hline Yes & $229(64.7)$ \\
\hline No & $108(30.5)$ \\
\hline I don't know & $17(4.8)$ \\
\hline \multicolumn{2}{|c|}{$\begin{array}{l}\text { Have you been taught anything about off-label and unlicensed } \\
\text { medicine in paediatrics? }\end{array}$} \\
\hline Yes & $157(44.4)$ \\
\hline No & $197(55.6)$ \\
\hline \multicolumn{2}{|c|}{$\begin{array}{l}\text { Do you think that your curriculum should have more paedia- } \\
\text { tric courses? }\end{array}$} \\
\hline Yes & $287(81.1)$ \\
\hline No & $44(12.4)$ \\
\hline I don't know & $23(6.5)$ \\
\hline
\end{tabular}

almost one-third of the respondents (30.5\%) reported having had no exposure to paediatric dosing or dose calculation courses during their education. Moreover, $55.6 \%$ were unfamiliar with the concept of off-label or unlicensed paediatric medicine use. Overall, the majority of the students (81.1\%) reported that there was a need for more paediatric-related topics to be
Table 4: Self-reported competency of final-year pharmacy students in Jordan regarding paediatric pharmaceutical care $(\mathrm{N}=354)$

\begin{tabular}{|c|c|c|c|}
\hline \multirow[t]{2}{*}{ Item } & \multicolumn{3}{|c|}{ Response, n (\%) } \\
\hline & Yes & No & $\begin{array}{c}\text { I } \\
\text { don't } \\
\text { know }\end{array}$ \\
\hline $\begin{array}{l}\text { When you graduate, will you be } \\
\text { able to deal with paediatric patients } \\
\text { and give treatment recommend- } \\
\text { ations? }\end{array}$ & $\begin{array}{c}157 \\
(44.4)\end{array}$ & $\begin{array}{c}77 \\
(21.8)\end{array}$ & $\begin{array}{c}120 \\
(33.9)\end{array}$ \\
\hline $\begin{array}{l}\text { Do you think that you will be } \\
\text { able to calculate paediatric doses? }\end{array}$ & $\begin{array}{c}212 \\
(59.9)\end{array}$ & $\begin{array}{c}86 \\
(24.3)\end{array}$ & $\begin{array}{c}56 \\
(15.8)\end{array}$ \\
\hline $\begin{array}{l}\text { Do you think that you have the } \\
\text { training and ability to counsel } \\
\text { paediatric patients' parents or } \\
\text { guardians? }\end{array}$ & $\begin{array}{c}195 \\
(55.1)\end{array}$ & $\begin{array}{c}100 \\
(28.2)\end{array}$ & $\begin{array}{c}59 \\
(16.7)\end{array}$ \\
\hline $\begin{array}{l}\text { Do you think that you have the } \\
\text { ability to monitor side-effects in } \\
\text { children? }\end{array}$ & $\begin{array}{c}180 \\
(50.8)\end{array}$ & $\begin{array}{c}99 \\
(28)\end{array}$ & $\begin{array}{c}75 \\
(21.2)\end{array}$ \\
\hline
\end{tabular}

incorporated into the curriculum [Table 3]. In terms of their perceived ability to deal with and treat paediatric patients after graduation, many respondents were either unsure or believed that they would not be able to recommend treatment for paediatric patients (55.7\%), calculate paediatric doses (40.1\%), counsel the parents or guardians of paediatric patients (44.9\%) or monitor side-effects in children (49.2\%) [Table 4].

With regards to their responses to realistic paediatric case scenarios, most students scored either one (33.9\%) or two (28.2\%) points out of five [Figure 1A]. In addition, there was a greater percentage of incorrect compared to correct responses for each case scenario, except for the case scenario involving fever [Figure 1B]. Overall, there were no significant differences in the students' knowledge, attitudes or competency according to type of degree or university attended $(P>0.05)$.

\section{Discussion}

The present study sheds light on the self-reported knowledge, attitudes and competency of final-year pharmacy students in Jordan regarding paediatric pharmaceutical care, including assessment, treatment and dosage. Although a previous study investigated the paediatric content of pharmacy curricula in different countries, the current study is, to the best of the authors' knowledge, the first to directly explore pharmacy students' perceptions and attitudes regarding this topic. ${ }^{18}$ Overall, the current study exposed a perceived lack of paediatricrelated content in the pharmacy curricula of Jordanian universities, with most students highlighting the need for the inclusion of more paediatric-related topics in their courses. This raises concerns regarding the ability of newly-graduated pharmacists to deal with paediatric cases. 
A

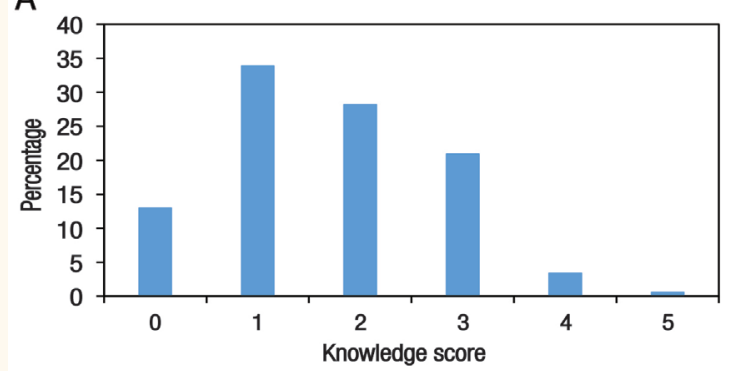

B

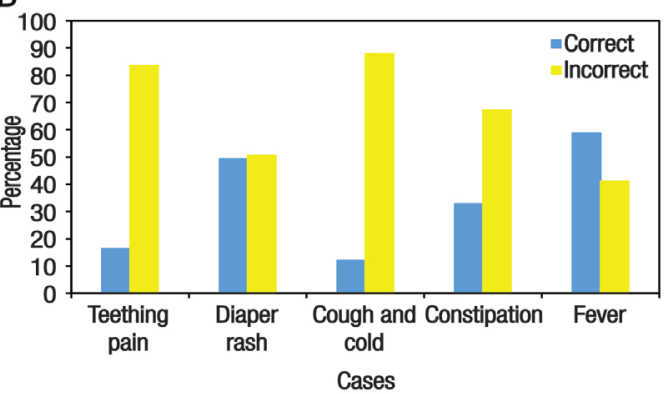

Figure 1: Distribution of (A) total knowledge scores* and (B) correct and incorrect responses among final-year pharmacy students in Jordan presented with realistic paediatric case scenarios $(\mathrm{N}=354)$.

"For each of the five case scenarios, correct responses were given a score of one, with total scores of zero and five corresponding to no or perfect knowledge, respectively.

Pharmacists should be sufficiently knowledgeable of paediatric pharmaceutical care so as to ensure that paediatric patients are prescribed suitable, safe and effective medications. ${ }^{19}$ This is especially important in light of the fact that up to $70 \%$ and $95 \%$ of medicines prescribed to paediatric patients and neonates, respectively, are unlicensed or off-label; moreover, the risk of adverse drug events in the paediatric population is three times greater than for adults. ${ }^{20-22}$ Several studies have reported high rates of pharmacy-related medication errors when treating children, including a retrospective study of outof-hospital medication errors among young children in the USA between 2002-2012.23-25 Generally, the majority of pharmacy-related errors occur when a pharmacist is not able to identify prescription errors, gives incorrect drug administration instructions or mislabels a medication. ${ }^{26}$ There is considerable evidence to suggest that a well-trained pharmacist can reduce the rate of medication errors, specifically in younger children, for whom such errors can be fatal. ${ }^{27,28}$

In the current study, more than half of the students reported being unfamiliar with the concept of off-label or unlicensed paediatric medicine use during the course of their education. Many healthcare professionals have similarly reported being unfamiliar with the off-label or unlicensed use of medicine among children in their own practices. ${ }^{29-31}$ A previous study in Scotland found that $30 \%$ of pharmacists were unaware of off-label medicine use in children, with the majority of respondents having gained such knowledge in clinical practice rather than during their formal education..$^{30}$ Both general practitioners and paediatricians have reported receiving insufficient information regarding off-label and unlicensed medicine use in children during undergraduate education. . $^{29,31}$

Almost one-third of respondents in the current study reported not having taken any paediatric dose calculation courses during their education. Dosing mistakes-such as 10-fold dose calculation errors, in which wrong dose calculations result from missing one or more decimal points-are amongst the most fatal drug-related problems in paediatric care. ${ }^{32-34}$ Compared to adults, dosing in paediatric patients is individualised and may depend on different factors for each case. ${ }^{35}$ Accordingly, extra caution should be taken when dealing with paediatric dosages, especially when dispensing medications with a narrow therapeutic index. ${ }^{36}$

Overall, respondents in the current study had grave concerns regarding their ability to deal with and treat paediatric patients. This highlights the importance of covering such topics in pharmacy courses. Previous studies have indicated that healthcare professionals fail to adequately communicate with paediatric patients or convey treatment information to the child's parents. ${ }^{29-31}$ Pharmacy students should therefore be trained to deal with paediatric patients and their parents in communication courses. Furthermore, dose calculations and adjustments should be covered extensively in pharmacokinetics courses to ensure that future pharmacists are able to dispense medicine in accurate doses and reduce the frequency of dosing errors in children. Another important factor is the ability to monitor side-effects in children; previous research has shown that pharmacists often fail to detect and report adverse drug reactions. ${ }^{37}$ Further education regarding pharmacovigilance, specifically in paediatric patients, will optimise the role of future pharmacists in paediatric pharmaceutical care. Another suggestion is to mandate postgraduate certification courses in paediatrics prior to actual practice.

Worldwide, there is growing recognition that pharmacy education needs to be developed and improved so as to better prepare graduates to provide paediatric pharmaceutical care. ${ }^{11,38}$ In the current study, most respondents had low knowledge scores when faced with basic real-life paediatric scenarios. Alarmingly, although the cases covered only simple ailments which are very common in paediatric care (e.g. diaper rash, teething, constipation, etc.), most students were unable to answer 
correctly. Moreover, such students were in their final year of study and would very soon be registered pharmacists. This finding is therefore of major concern and highlights the importance of hands-on paediatric training along with formal education. ${ }^{39}$ A didactic educational approach that fails to include a research component and incorporates only minimal hands-on training may lead to pharmacists lacking real-world experience and being unable to deal with general and primary care cases. ${ }^{40,41}$ One obstacle in Jordan may be the large number of students per class in pharmacy schools, especially in public universities. The implementation of a pre-registration year of practice for pharmacy graduates may positively influence their ability to deal with different patient populations, such as children. ${ }^{41}$

In the present study, no significant differences in knowledge or attitudes were noted between final-year pharmacy undergraduate and doctoral students according to type of degree. This finding was unexpected as doctoral students undergo more specialised paediatric education in the form of a compulsory course in paediatric therapeutics and a hospital rotation in paediatric wards. Given this additional training, it might be supposed that such students should display greater knowledge or enhanced clinical abilities when faced with paediatric case scenarios. ${ }^{42}$ Furthermore, no significant differences were observed between pharmacy students at public or private universities. It should be noted that all university programmes and curricula in Jordan are subject to the guidelines and recommendations of the Accreditation and Quality Assurance Commission for Higher Education Institutions, thereby leading to similar curricula for the majority of pharmacy programmes in the country.

This study was subject to several limitations. Firstly, no measures were taken to ensure that students did not consult or refer to external sources when answering knowledge questions; however, this is unlikely considering the low knowledge scores. Secondly, the participants' knowledge was scored on a Likert rather than a binomial scale; the latter might have allowed for more in-depth analysis of the responses in comparison to the participants' demographic characteristics and potentially reduced bias. Thirdly, some of the questions may have been difficult to answer due to the wording, which could have been clearer; thus, clarity may have affected the validity of the findings. Furthermore, items in the questionnaire were perhaps too general-for example when inquiring about respondents' knowledge of the term 'paediatrics'-however, this was deemed necessary as the study took place in an Arabic-speaking country where laypeople may not be aware of such terms. Nevertheless, the current study was exploratory in nature and these findings could be considered a benchmark for further in-depth studies in paediatric pharmacy education.

\section{Conclusion}

Pharmacists play a vital role in assuring the safe and effective administration of medications to paediatric patients. The results of this study revealed that, according to final-year pharmacy students, the current pharmacy curricula taught during undergraduate and doctoral programmes in Jordan is insufficient with regards to paediatric pharmaceutical care. The students had low confidence regarding their ability to deal with paediatric patients, with most not able to make correct recommendations during basic case scenarios, counsel children and their parents/guardians or calculate correct drug dosages. Pharmacy students should therefore undergo more extensive education and training in these areas, perhaps during a mandatory pre-registration year of practice.

\section{ACKNOWLEDGEMENTS}

The preliminary version of this study was presented at the Health Services Research and Pharmacy Practice Conference on 12-13 April 2018 at the University of Newcastle, Newcastle upon Tyne, UK. An abstract of this oral presentation was published in the International Journal of Pharmacy Practice in March 2018, Volume 26, Issue S1, Pp. 9-10.

\section{CONFLICT OF INTEREST}

The authors declare no conflicts of interest.

\section{FUNDING}

This study was funded with the aid of a grant from the Deanship of Research at Jordan University of Science \& Technology (grant \#20160191).

\section{References}

1. Bhatt-Mehta V, Buck ML, Chung AM, Farrington EA, Hagemann TM, Hoff DS, et al. Recommendations for meeting the pediatric patient's need for a clinical pharmacist: A joint opinion of the Pediatrics Practice and Research Network of the American College of Clinical Pharmacy and the Pediatric Pharmacy Advocacy Group. Pharmacotherapy 2013; 33:243-51. https://doi.org/10.1002/phar.1246

2. Condren ME, Haase MR, Luedtke SA, Gaylor AS. Clinical activities of an academic pediatric pharmacy team. Ann Pharmacother 2004; 38:574-8. https://doi.org/10.1345/aph.1D384.

3. Larochelle JM, Ghaly M, Creel AM. Clinical pharmacy faculty interventions in a pediatric intensive care unit: An eight-month review. J Pediatr Pharmacol Ther 2012; 17:263-9. https://doi. org/10.5863/1551-6776-17.3.263. 
4. Feudtner C, Dai D, Hexem KR, Luan X, Metjian TA. Prevalence of polypharmacy exposure among hospitalized children in the United States. Arch Pediatr Adolesc Med 2012; 166:9-16. https://doi.org/10.1001/archpediatrics.2011.161.

5. Lasky T. Estimates of pediatric medication use in the United States: Current abilities and limitations. Clin Ther 2009; 31:436-45. https://doi.org/10.1016/j.clinthera.2009.02.003.

6. Gu Q, Dillon CF, Burt VL. Prescription drug use continues to increase: U.S. prescription drug data for 2007-2008. NCHS Data Brief 2010; 42:1-8.

7. Prescott WA Jr, Dahl EM, Hutchinson DJ. Education in pediatrics in US colleges and schools of pharmacy. Am J Pharm Educ 2014; 78:51. https://doi.org/10.5688/ajpe78351.

8. Kharmeh S. Evaluating the quality of health care services in the Hashemite Kingdom of Jordan. Int J Bus Manag 2012; 7:195-205. https://doi.org/10.5539/ijbm.v7n4p195.

9. Wazaify M, Abood E, Tahaineh L, Albsoul-Younes A. Jordanian community pharmacists' experience regarding prescription and nonprescription drug abuse and misuse in Jordan: An update. J Subst Use 2017; 22:463-8. https://doi.org/10.1080/14659891. 2016.1235734 .

10. Cho HJ, Hong SJ, Park S. Knowledge and beliefs of primary care physicians, pharmacists, and parents on antibiotic use for the pediatric common cold. Soc Sci Med 2004; 58:623-9. https://doi. org/10.1016/S0277-9536(03)00231-4.

11. Aucoin RG, Buck ML, Dupuis LL, Dominguez KD, Smith KP. Pediatric pharmacotherapeutic education: Current status and recommendations to fill the growing need. Pharmacotherapy 2005; 25:1277-82. https://doi.org/10.1592/phco.2005.25.9.1277.

12. Lavoie A, Gerber P. Pediatric pharmacotherapy content of Canadian undergraduate pharmacy curricula. Can Pharm J (Ott) 2008; 141:228-33. https://doi.org/10.3821/1913701X200 8141228PPCOCU20CO2.

13. Meyers RS, Costello-Curtin J. Implementing a pediatric pharmacy educational program for health-system pharmacists. Am J Pharm Educ 2011; 75:205. https://doi.org/10.5688/ajpe7 510205 .

14. Small L, Schuman A, Reiter PD. Training program for pharmacists in pediatric emergencies. Am J Health Syst Pharm 2008; 65:649-54. https://doi.org/10.2146/ajhp070353.

15. Benavides S, Huynh D, Morgan J, Briars L. Approach to the pediatric prescription in a community pharmacy. J Pediatr Pharmacol Ther 2011; 16:298-307. https://doi.org/10.5863/15 51-6776-16.4.298.

16. Boucher EA, Burke MM, Johnson PN, Klein KC, Miller JL; Advocacy Committee for the Pediatric Pharmacy Advocacy Group. Minimum requirements for core competency in pediatric pharmacy practice. J Pediatr Pharmacol Ther 2015; 20:481-4. https://doi.org/10.5863/1551-6776-20.6.481.

17. Munzenberger PI, Thomas RL, Edwin SB, Tutag-Lehr V Pharmacists' perceived knowledge and expertise in selected pediatric topics. J Pediatr Pharmacol Ther 2011; 16:47-54.

18. Horton ER, Belliveau P. Pediatric pharmacotherapy in the PharmD curriculum: Course design and student self-assessment of learning outcomes achievement. Curr Pharm Teach Learn 2014; 6:277-83. https://doi.org/10.1016/j.cptl.2013.11.008.

19. Hepler CD, Strand LM. Opportunities and responsibilities in pharmaceutical care. Am J Hosp Pharm 1990; 47:533-43.

20. Pandolfini $\mathrm{C}$, Bonati $\mathrm{M}$. A literature review on off-label drug use in children. Eur J Pediatr 2005; 164:552-8. https://doi.org/ 10.1007/s00431-005-1698-8.

21. Conroy S, McIntyre J, Choonara I. Unlicensed and off label drug use in neonates. Arch Dis Child Fetal Neonatal Ed 1999; 80:F142-5. https://doi.org/10.1136/fn.80.2.F142.

22. Kaushal R, Bates DW, Landrigan C, McKenna KJ, Clapp MD,
Federico F, et al. Medication errors and adverse drug events in pediatric inpatients. JAMA 2001; 285:2114-20. https://doi. org/10.1001/jama.285.16.2114.

23. Costa LA, Valli C, Alvarenga AP. Medication dispensing errors at a public pediatric hospital. Rev Lat Am Enfermagem 2008; 16:812-17. https://doi.org/10.1590/S0104-11692008000500003.

24. Smith MD, Spiller HA, Casavant MJ, Chounthirath T, Brophy TJ, Xiang $\mathrm{H}$. Out-of-hospital medication errors among young children in the United States, 2002-2012. Pediatrics 2014; 134:867-76. https://doi.org/10.1542/peds.2014-0309.

25. Miller MR, Robinson KA, Lubomski LH, Rinke ML, Pronovost PI. Medication errors in paediatric care: A systematic review of epidemiology and an evaluation of evidence supporting reduction strategy recommendations. Qual Saf Health Care 2007; 16:116-26. https://doi.org/10.1136/qshc.2006.019950.

26. Jeetu G, Girish T. Prescription drug labeling medication errors: A big deal for pharmacists. J Young Pharm 2010; 2:107-11. https://doi.org/10.4103/0975-1483.62218.

27. Matsui D. Current issues in pediatric medication adherence. Paediatr Drugs 2007; 9:283-8. https://doi.org/10.2165/0014858 1-200709050-00001.

28. Eisenhut M, Sun B, Skinner S. Reducing prescribing errors in paediatric patients by assessment and feedback targeted at prescribers. ISRN Pediatr 2011; 2011:545681. https://doi.org/10. $5402 / 2011 / 545681$

29. Ekins-Daukes S, Helms PI, Taylor MW, McLay IS. Off-label prescribing to children: Attitudes and experience of general practitioners. Br J Clin Pharmacol 2005; 60:145-9. https://doi. org/10.1111/j.1365-2125.2005.02397.x.

30. Stewart D, Rouf A, Snaith A, Elliott K, Helms PJ, McLay JS. Attitudes and experiences of community pharmacists towards paediatric off-label prescribing: A prospective survey. Br J Clin Pharmacol 2007; 64:90-5. https://doi.org/10.1111/j.1365-2125. 2007.02865.x.

31. Mukattash TL, Wazaify M, Khuri-Boulos N, Jarab A, Hawwa AF, McElnay JC. Perceptions and attitudes of Jordanian paediatricians towards off-label paediatrics prescribing. Int J Clin Pharm 2011; 33:964-73. https://doi.org/10.1007/s11096-011-9569-z.

32. Yin HS, Dreyer BP, Moreira HA, van Schaick L, Rodriguez L, Boettger S, et al. Liquid medication dosing errors in children: Role of provider counseling strategies. Acad Pediatr 2014; 14:262-70. https://doi.org/10.1016/j.acap.2014.01.003.

33. Cohen M, Vaida A, Litman RS, Jenkins RH. Error-prone abbreviations and dose expressions. Anesth Analg 2016; 122:581. https://doi.org/10.1213/ANE.0000000000000984.

34. Scott CS, Deloatch KH. Advanced pediatric pharmacotherapy: An elective course with service-learning. Am J Pharm Educ 1998; 62:420-6. https://doi.org/aj620410.pdf.

35. Cella M, Danhof M, Della Pasqua O. Adaptive trials in paediatric development: Dealing with heterogeneity and uncertainty in pharmacokinetic differences in children. Br J Clin Pharmacol 2012; 74:346-53. https://doi.org/10.1111/j.1365-2125.2012.04187.x.

36. Mukattash TL, Hayajneh WA, Ibrahim SM, Ayoub A, Ayoub N, Jarab AS, et al. Prevalence and nature of off-label antibiotic prescribing for children in a tertiary setting: A descriptive study from Jordan. Pharm Pract (Granada) 2016; 14:725. https://doi. org/10.18549/PharmPract.2016.03.725.

37. Pellegrino P, Carnovale C, Cattaneo D, Perrone V, Antoniazzi S, Pozzi M, et al. Pharmacovigilance knowledge in family paediatricians: A survey study in Italy. Health Policy 2013; 113:216-20. https://doi.org/10.1016/j.healthpol.2013.08.006.

38. Eiland LS, Benner K, Gumpper KF, Heigham MK, Meyers R, Pham K, et al. ASHP-PPAG guidelines for providing pediatric pharmacy services in hospitals and health systems. Am J Health Syst Pharm 2018; 75:1151-65. https://doi.org/10.2146/aihp170827. 
39. Johnson TJ. Pharmacist work force in 2020: Implications of requiring residency training for practice. Am J Health Syst Pharm 2008; 65:166-70. https://doi.org/10.2146/ajhp070231.

40. Mukattash TL, Alattar M, Abu-Farha RK, Alsous M, Jarab AS, Darwish Elhajji FW, et al. Evaluating scientific research knowledge and attitude among medical representatives in Jordan: A cross-sectional survey. Curr Clin Pharmacol 2017; 12:245-52. https://doi.org/10.2174/1574884712666170828124950.
41. Jee S, Schafheutle E, Noyce PR. Changes in behavioural professionalism during pre-registration training and early pharmacy practice. In: Abstracts of the papers presented at the Health Services Research \& Pharmacy Practice Conference, 3-4 April 2014, University of Aberdeen, Aberdeen, UK. Int J Pharm Pract 2014; 22:S41-2.

42. Mukattash TL, Nuseir KQ, Biltaji E, Jarab AS, Alefan Q Students' perceptions of pharmacy as a specialization and their future career, a cross sectional study of final year pharmacy students in Jordan. Jordan J Pharm Sci 2015; 8:195-204 